\title{
PEMENTASAN TEATER I LA GALIGO SEBAGAI SARANA KOMUNIKASI NILAI-NILAI LUHUR BUDAYA INDONESIA DI KANCAH INTERNASIONAL ${ }^{12}$
}

\author{
Achmad Zulfikar \\ Program Studi Ilmu Hubungan Internasional \\ Fakultas Ilmu Sosial dan Ilmu Politik \\ Universitas Muhammadiyah Yogyakarta \\ Email: apa@kabarfikar.com
}

\begin{abstract}
Cultural export is commonly done by many countries today. Recent examples can be seen from South Korea to export their culture such as movies, music, style of dress, style of speaking, and the various activities undertaken by his idol artist to the international community. This effort should be positively addressed by Indonesia, where we can perform similar actions by exporting Indonesian culture abroad. One of them is I La Galigo that have been staged in more than 7 countries. I La Galigo is one of the traditional culture of origin from South Sulawesi is also literature that is inspired the stage has been recognized by UNESCO. The findings of this study which theater I La Galigo effective as a means of communication and diplomacy among nations that effectively deliver the noble values such as courage, culture wealth, and a shy demeanor and empathy of Indonesia people to the international arena. Furthermore, researchers expect this paper will inspire the local cultural observer to export culture and the courage to show the culture of Indonesia in the international arena with relevant agencies facilitated.
\end{abstract}

Keywords: I La Galigo Theatre, Communication, Diplomacy, Indonesia Culture, International Relations

\begin{abstract}
Abstrak
Ekspor budaya merupakan hal yang lazim dilakukan oleh berbagai negara saat ini. Contoh yang terbaru dapat dilihat dari Korea Selatan yang dapat mengekspor kebudayaannya seperti: film, musik, gaya berpakaian, gaya berbicara, dan berbagai aktivitas yang dilakukan oleh artis idolanya kepada masyarakat internasional. Upaya ini seharusnya disikapi secara positif oleh Indonesia, dimana kita dapat melakukan tindakan-tindakan serupa dengan melakukan ekspor kebudayaan Indonesia ke luar negeri. Salah satunya yakni I La Galigo yang telah dipentaskan di lebih dari 7 negara. I La Galigo merupakan salah satu kebudayaan tradisional asal Sulawesi Selatan yang juga karya sastra yang merupakan inspirasi dari pentas tersebut telah diakui oleh UNESCO. Temuan dari penelitian ini yakni pementasan teater I La Galigo efektif sebagai sarana komunikasi dan diplomasi antarbangsa yang efektif mengantarkan nilai-nilai luhur budaya Indonesia seperti keberanian, kekayaan budaya, serta sikap malu dan empati orang Indonesia ke kancah internasional. Selanjutnya peneliti mengharapkan makalah ini dapat menginspirasi para pemerhati budaya daerah untuk melakukan ekspor budaya dan memberanikan diri untuk menunjukkan kebudayaan Indonesia di kancah internasional dengan difasilitas instansi terkait.
\end{abstract}

Kata Kunci: Teater I La Galigo, Komunikasi, Diplomasi, Budaya Indonesia, Hubungan Internasional

\footnotetext{
${ }^{1}$ Makalah hasil pengembangan dari "Pementasan Teater I La Galigo sebagai Rebranding Indonesia di Kancah Internasional" yang dikompetisikan pada Call for Paper "Budaya Pop Indonesia sebagai Media Rebranding" dalam rangkaian Communication Awards 2012 yang diselenggarakan oleh Korps Mahasiswa Ilmu Komunikasi Universitas Muhammadiyah Yogyakarta. Dipresentasikan dihadapan Dewan Juri pada 19 Oktober 2012.

2 Makalah telah dipresentasikan dalam Konferensi Internasional Budaya Daerah (KIBD) III yang diselenggarakan oleh Ikatan Dosen Budaya Daerah Indonesia (Ikadbudi) pada 7-8 Desember 2013 di Universitas Veteran Bangun Nusantara (Univet Bantara), Sukoharjo, Indonesia.
} 


\section{A. PENDAHULUAN}

Derasnya arus globalisasi kini tak terhindarkan lagi. Bebasnya budaya suatu negara berbaur dengan budaya negara lain sudah merupakan hal yang tidak asing lagi. Beberapa budaya membawa dampak positif maupun negatif bagi budaya lain. Saat ini budaya pop yang sedang disukai oleh kalangan anak muda berasal dari Korea Selatan atau biasa dikenal dengan istilah Korean Wave (Gelombang Korea). Adapun budaya yang di ekspor oleh negara tersebut antara lain: film, musik, gaya berpakaian, gaya berbicara, dan berbagai aktivitas yang dilakukan oleh artis idolanya.

Dari fenomena ini, dampak tidak langsung yang diterima oleh Korea yakni meningkatnya jumlah wisatawan asing ke negaranya. Bersamaan dengan hal tersebut, muncul juga dampak negatif bagi negara yang terkena akibat dari Korean Wave, yakni terkikisnya budaya setempat berupa nilai atau norma yang telah berlaku, serta mempengaruhi gaya hidup seseorang.

Hal ini dapat kita lihat sebagai ancaman, dan peluang bagi Indonesia. Ancaman dari serbuan gelombang Korea ini yakni tergerusnya budaya Indonesia yang menjunjung tinggi nilai kesusilaan, sedangkan peluang bagi Indonesia dapat disikapi dengan melakukan ekspor budaya baik berupa nilai atau norma, maupun kesenian sebagai upaya mempromosikan budaya Indonesia. Selanjutnya ekspor budaya ini justru dapat menjadi sarana mengkomunikasikan nilai-nilai luhur budaya Indonesia di kancah internasional.

Kebudayaan yang ingin dijadikan ikon budaya yakni salah satu kebudayaan tradisional asal Sulawesi Selatan yang sudah mulai mendunia yang dikenal dengan nama I La Galigo. I La Galigo merupakan karya sastra klasik yang lahir di tanah Bugis, Sulawesi Selatan yang berasal dari abad ke-14. Karya ini merupakan karya sastra yang terpanjang di dunia dengan keseluruhan jumlahnya 6000 folio. Karya ini juga di kenal dengan istilah Sureq La Galigo. I La Galigo kini telah diakui oleh United Nations Educational, Scientific, and Cultural Organization (UNESCO) sebagai Memory of the World yang juga merupakan warisan kebudayaan dunia. (http://www.unesco.org/new/en/communication-andinformation/flagship-project-activities/memory-of-the-world/register/full-list-of-registeredheritage/registered-heritage-page-5/la-galigo, diakses tanggal 10 November 2013)

Seiring berjalannya waktu I La Galigo tidak hanya sekedar karya sastra yang merupakan artefak kebudayaan. I La Galigo kini telah bertransformasi menjadi modern dan dapat dimaknai oleh masyarakat luas sehingga dikenal dengan nama pementasan teater I La Galigo. Transformasi ini menjadi penting karena nilai-nilai yang luhur yang dibawa ke atas pentas ini merupakan nilai-nilai luhur yang diadaptasi dari sastra I La Galigo yang telah diakui oleh dunia internasional.

\section{B. SENI TEATER SEBAGAI ALAT KOMUNIKASI DAN DIPLOMASI ANTARBANGSA}

\section{Seni Teater dalam Perspektif Komunikasi}

Komunikasi adalah proses penyampaian suatu pesan oleh seseorang kepada orang lain untuk memberi tahu atau untuk mengubah sikap, pendapat, atau perilaku, baik langsung secara lisan, maupun tak langsung melalui media (Effendy, 1993:5).

Menurut Georg Gerbner komunikasi massa yaitu proses produksi dan distribusi yang berlandaskan teknologi dan lembaga dari arus pesan yang berkelanjutan serta paling luas dipunyai orang dalam masyarakat industri. Dalam variannya komunikasi massa atau komunikasi melalui media massa terdiri atas: surat kabar, radio, televisi, internet dan sebagainya. (Rakhmat, 1999: 188) 
Seni teater merupakan salah satu bentuk komunikasi massa. Hal ini didasarkan pada fungsi dari teater sebagai salah satu media massa, maka peran dan fungsi teater sendiri sama dengan peran dan fungsi dari komunikasi massa, yaitu sebagai sarana penyebaran informasi mengenai kejadian-kejadian dalam lingkungan, baik di luar maupun di dalam masyarakat.

Dalam konteks hubungan media dengan publik seperti halnya media massa yang lain, seni teater juga menjalankan fungsi utama media massa seperti yang dikemukakan oleh Harold D. Laswell (Darwanto, 2007:32-33) sebagai berikut:

1) The surveillance of the Environment. Artinya media massa mempunyai fungsi sebagai pengamat lingkungan, yaitu sebagai pemberi informasi tentang hal-hal yang berada di luar jangkauan penglihatan masyarakat.

2) The corrections of the parts of society to the environment. Artinya media massa berfungsi untuk melakukan seleksi, evaluasi dan interpretasi informasi. Dalam hal ini peranan media adalah melakukan seleksi mengenai apa yang pantas dan perlu untuk disiarkan.

3) The transmition of the social heritage from one generation to the next. Artinya media merupakan sarana penyampaian nilai dan warisan sosial budaya dari satu generasi ke generasi lainnya. Fungsi ini merupakan fungsi pendidikan oleh media massa.

Di samping itu perlu disadari bahwa seni teater merupakan cabang kesenian yang unggul dibandingkan cabang seni lainnya, karena seni teater ini paling banyak melibatkan unsur-unsur lain. Tidak hanya pelaku-pelaku teaternya tetapi juga unsur-unsur seni lainnya seperti: seni rupa, seni musik, seni tari dan seni sastra. Dari unsur-unsur seni ini tentunya akan memberikan seni teater kebebasan untuk mengeksplorasi gagasan maupun gerakan dari seni-seni lainnya untuk dipentaskan di depan khalayak.

\section{Seni Teater dalam Perspektif Diplomasi Antarbangsa}

Seni teater dalam sudut pandang diplomasi antarbangsa termasuk ke dalam kelompok diplomasi kebudayaan. Diplomasi kebudayaan secara terpisah terdiri atas kata 'diplomasi' dan 'kebudayaan' yang dapat dipahami bahwa pengertian diplomasi adalah usaha suatu negara-bangsa (nation-state) untuk memperjuangkan kepentingan nasional di kalangan masyarakat internasional. (K. J. Holsti dalam Warsito dan Wahyuni, 2007:2). Dalam hal ini diplomasi diartikan tidak sekedar sebagai perundingan, melainkan semua upaya hubungan luar negeri. (S. L. Roy dalam Warsito dan Wahyuni, 2007:3).

Sedangkan kebudayaan secara makro atau dalam pengertian umum segala hasil dan upaya budi daya manusia terhadap lingkungan (J.W.M Bakker SJ dalam Warsito dan Wahyuni, 2007:3). Ada juga yang secara makro mengartikan kebudayaan sebagai keseluruhan sistem gagasan, tindakan, dan hasil karya manusia dalam rangka kehidupan masyarakat yang dijadikan milik diri manusia dengan belajar (Kuntjaraningrat dalam Warsito dan Wahyuni, 2007:3).

Jika pengertian makro dari kebudayaan ini dikaitkan dengan diplomasi, maka diplomasi kebudayaan sesungguhnya adalah merupakan satu-satunya jenis diplomasi yang dimiliki manusia. Sebab diplomasi apapun yang dilakukan manusia, baik itu diplomasi ekonomi, diplomasi militer, dan lain-lain termasuk sebagai hasil budaya. Namun demikian, apa yang hendak dibahas yakni diplomasi kebudayaan dalam arti kebudayaan mikro, yakni yang biasanya termanifestasikan dalam pendidikan, kesenian, ilmu pengetahuan dan olahraga. Lebih mikro lagi, dan ini yang justru lebih sering dianggap sebagai 'konvensi' adalah kebudayaan yang menitikberatkan pada pemanfaatan 'kesenian'. (Warsito dan Wahyuni 2007:3) 
Dengan demikian diplomasi kebudayaan dapat diartikan sebagai usaha suatu negara untuk memperjuangkan kepentingan nasionalnya melalui dimensi kebudayaan, baik secara mikro seperti pendidikan, ilmu pengetahuan, olahraga, dan kesenian, ataupun secara makro sesuai dengan ciri-ciri khas yang utama, misalnya propaganda dan lain-lain, yang dalam pengertian konvensional dapat dianggap bukan politik, ekonomi, ataupun militer. (K.J Holsti dalam Warsito dan Wahyuni, 2007:4)

Selanjutnya kita perlu mengetahui tujuan dari diplomasi kebudayaan adalah untuk mempengaruhi pendapat umum (masyarakat negara lain) guna mendukung suatu kebijaksanaan politik luar negeri tertentu. Pola umum yang biasanya terhadi dalam hubungan diplomasi kebudayaan adalah antara masyarakat (suatu negara tertentu) dengan masyarakat (negara lain). Pengertian di atas merupakan bentuk pemaknaan dari sudut pandang politik yang sarat kepentingan, apabila dipahami sebagai sarana berkomunikasi, maka penerimaan masyarakat negara tersebut terhadap sesuatu yang ditampilkan oleh negara lain merupakan salah satu indikator keberhasilan diplomasi kebudayaan yang dilakukan.

Dari penjelasan di atas sudah sangat jelas bahwa pementasan teater I La Galigo yang merupakan kebudayaan Indonesia ketika dipentaskan di luar negeri, maka termasuk ke dalam diplomasi kebudayaan. Sebagaimana juga disebutkan bahwa kesenian merupakan bagian dari dimensi kebudayaan mikro. Posisi ini semakin dikuatkan dengan tujuan diplomasi kebudayaan sebagai sarana berkomunikasi, apabila pementasan teater I La Galigo diterima dengan baik oleh negara lain, maka dapat dipastikan diplomasi kebudayaan yang mengkomunikasikan nilai-nilai luhur budaya Indonesia telah tersampaikan secara efektif.

\section{AWAL MULA TEATER I LA GALIGO}

Pementasan teater I La Galigo pertama kali dibawakan ke atas pentas oleh Robert Wilson seniman asal Texas, Amerika Serikat. Wilson mulai tertarik untuk mengangkat karya sastra ini ke atas pentas sejak tahun 2000 atas dorongan Rhoda Grauer dan Restu Kusumaningrum, keinginan Wilson juga di dukung oleh semangat Change Performing Arts dan Bali Purnati Center for the Arts.

Proses yang dilalui oleh Wilson sebelum memulai debut pertamanya mementaskan teater I La Galigo pada tahun 2004, dimulai dengan melakukan pendalaman bersama tim akademisi budaya Sulawesi Selatan yang memberikan saran terkait dengan upaya untuk menghidupkan epik sastra I La Galigo di atas pentas.

Kecakapan Wilson dalam mengelola teater I La Galigo ini dibuktikan dengan pementasan yang telah dilakukan di berbagai negara termasuk Indonesia sebagai berikut: (1) Singapore, Esplanade, Theatres on the Bay, 12 - 13 March 2004, (2) Amsterdam, Het Muziektheater, 12, 14, 15 May 2004, (3) Barcelona, Forum Universal de les Cultures, Teatro Lliure, 20 - 23 May 2004, (4) Madrid, Teatro Español, 30 May-2 June 2004, (5) Lyon, Les Nuits de Fourvière Rhone, 8-10 June 2004, (6) Ravenna Festival, Teatro Alighieri, 18 - 20 June 2004, (7) New York, Lincoln Center, 13 - 16 July 2005, (8) Jakarta, Teater Tanah Airku - TMII, 10 - 12 December 2005, (9) Melbourne International Arts Festival, 19 - 23 October 2006, (10) Milano, Teatro Arcimboldi, 12 - 17 February 2008, (11) Taipei, Metropolitan Hall, Taipei Arts Festival, 7-10 August 2008, serta (12) Makassar, Indonesia, 23-24 April 2011. (sumber: http://www.changeperformingarts.it/shows/galigo/ilg.html, diakses tanggal 10 November 2013)

Berdasarkan tempat pementasan teater I La Galigo di atas menunjukkan bahwa teater ini sangat diminati oleh masyarakat Internasional tidak hanya di Indonesia. Salah satu alasan pementasan perdana dilakukan di Singapura atau Luar Negeri agar pementasan ini dapat terlebih dahulu dikenal secara meluas, hal ini didasarkan pada kebanggaan/prestige serta nilai suatu berita ketika terdapat acara dihelat di tempat yang terkenal. 
Tidak hanya itu, kehadiran Wilson untuk memperkenalkan sastra I La Galigo melalui seni teater memberikan dampak psikologis yang luar biasa terhadap masyarakat Indonesia. Upaya yang dilakukannya merupakan inspirasi bagi masyarakat Internasional secara umum, maupun masyarakat Sulawesi Selatan secara khusus untuk tetap melestarikan kebudayaannya.

Dalam hal ini Wilson yang merupakan seniman Internasional tentunya memiliki banyak pengalaman dalam mengelola seni teater dari berbagai aliran dan kini telah sukses dipentaskan di berbagai belahan dunia, tentunya memberikan peluang besar bagi sastra I La Galigo untuk berkembang lebih pesat dan dapat dikenal oleh seluruh dunia.

Tidak hanya itu, upaya pengembangan teater I La Galigo ini tentunya menantang. Karena dibutuhkan keahlian dalam menggabungkan antara tradisi dan folklor Bugis dengan bahasa teater kontemporer. Dalam hal ini, Wilson telah melakukan upaya tersebut dengan keahlian dan pengalaman yang dimilikinya dalam seni teater. Harapannya dengan pentas ini menjadi daya tarik untuk studi lebih lanjut dan meningkatkan kepekaan akademisi untuk mendalami kemegahan sastra I La Galigo ini.

\section{NILAI-NILAI LUHUR BUDAYA INDONESIA DALAM PEMENTASAN TEATER I LA GALIGO}

\section{Sinopsis Pementasan Teater I La Galigo: Perpaduan Budaya Modern dan Tradisional}

Petualangan liar karakter utama Sawerigading menerangi kosmologi dunia Bugis kuno, musik yang hidup, kostum yang khas, arsitektur kuno dan ritual orang Bugis, merupakan penggambaran seni-seni tradisional yang diangkat dalam pementasan teater I La Galigo.

Pementasan I La Galigo ini menjadi semakin menarik karena dipadukan dengan budaya modern yakni unsur kontemporer. Teater kontemporer yang akarnya tentu saja mengambil unsur budaya bangsa Indonesia sendiri kemudian dikolaborasikan dengan permainan lighting dan sound system yang canggih. Latar lampu warna-warni serta adegan seperti halnya sendratari (seni drama dan tari) yang dipadu dengan musik tradisional dan lagu-lagu tradisional Bugis tentu saja sangat memukau khususnya penikmat seni.

Adapun Teater I La Galigo termasuk pertunjukan teater kontemporer yang sangat minim dialog, sehingga terdapat banyak gerakan-gerakan tubuh yang memerlukan banyak interpretasi, baik itu bisa diinterpretasikan hubungannya dengan kebudayaan dari asal I La Galigo itu sendiri ataupun diinterpretasikan secara universal dari gerakan-gerakan tubuh yang dilakukan oleh para tokoh dalam teater tersebut. Gerakan-gerakan tubuh ini termasuk dalam komunikasi non-verbal (komunikasi tanpa kata-kata).

Komunikasi non-verbal acapkali dipergunakan untuk menggambarkan perasaan dan emosi. Jika pesan yang diterima melalui sistem verbal tidak menunjukkan kekuatan pesan maka dapat menerima tanda-tanda non-verbal lainnya sebagai pendukung.

Hal ini sejalan dengan Creative Director Bali Purnati Centre, Restu Iman Kusumaningrum, yang mengatakan, Robert Wilson memilih bentuk pertunjukan opera. Itu karena ia ingin memberikan kebebasan kepada penikmatnya untuk mencerap dan merasa. Kekuatan karya Robert bukan pada kata-kata, melainkan pada kepiawaiannya mengajak kita memainkan imajinasi. Drama I La Galigo memang tidak banyak memunculkan kata-kata. Kekuatan cerita hadir melalui harmonisasi musik tradisional, permainan cahaya, dan gerak. Satu-satunya penutur adalah seorang bissu (pendeta non gender) Bugis di sudut depan panggung. Itupun dengan bahasa Bugis klasik. Namun untuk memudahkan penikmatnya, alur cerita dijelaskan dengan display runing text di bagian atas panggung (http://edisantana.blogspot.com/2011/06/i-la-galigo-pujaan-dunia-yang-kembali.html, diakses tanggal 10 November 2013). 
Kehadiran unsur-unsur kebudayaan tradisional dan kebudayaan modern seperti yang telah dipaparkan di atas menunjukkan suatu keterpaduan yang harmonis antara keduanya. Hal ini sejalan dengan keinginan Wilson yang menyatakan, "I like working with an epic of this scale because the memory of the heroes is still present in the people of the village. It is a surreal world but yet it is real. The eyes and the hands of the performers become a concrete translation - with the colours, the sounds, the whispers, the perfumes - of the mystery and the divine. It is sensuality and beauty. There are very modern themes in the myth but the spectacle is mainly about the explosion of creativity. It is images, dance and music. The words are few: they are in the chant of the Bissu priest, the one who holds the secrets of the oral tradition of Sureq Galigo which guides the events between the sky and the earth." (http://www.changeperformingarts.it/shows/galigo/ilg.html, diakses tanggal 10 November 2013).

\section{Nilai-Nilai Luhur Budaya Indonesia}

Dari pementasan teater I La Galigo karya Robert Wilson terdapat beberapa hal yang penulis analisis terkait usaha-usaha mengkomunikasikan nilai-nilai luhur budaya Indonesia melalui pementasan teater I La Galigo ini. Adapun video dokumentasi pementasan teater I La Galigo diperoleh dari situs You Tube yang berdurasi 7 menit 13 detik. Video ini sangat singkat karena hak siar secara tidak langsung (rekaman) tidak diperbolehkan oleh pihak penyelenggara, sehingga hanya beberapa cuplikan yang relevan yang dapat dianalisis.

\section{Keberanian Orang Indonesia}

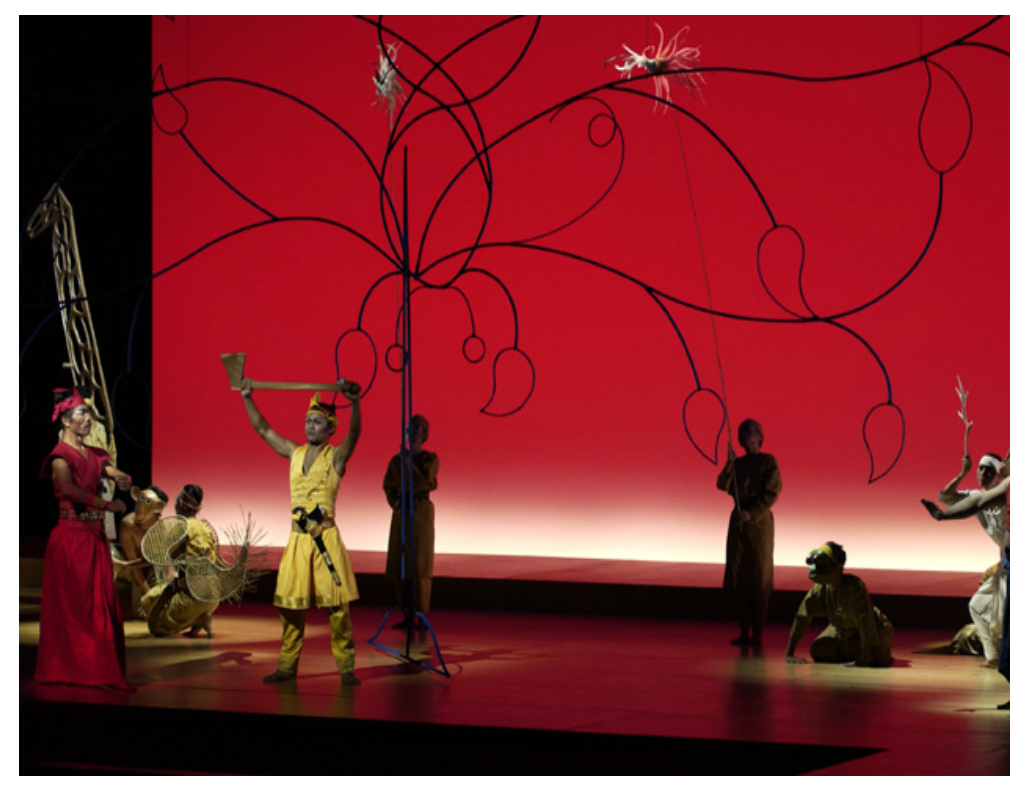

Keberanian orang Indonesia dimaknai dalam sikap yang ditunjukkan oleh tokoh utama Sawerigading di beberapa adegan selama pementasan. Keberanian tersebut ditunjukkan berulang-ulang di adegan yang berbeda sehingga menimbulkan kesan kepada penonton. Lebih lanjut, kata Berani dalam bahasa Bugis disebut Warani/Materru, dalam bahasa Makassar disebut Rewa, dalam bahasa Mandar dan Toraja disebut Barani, tak jarang Warani sering disematkan kepada individu manusia Bugis, Makassar, Mandar, dan Toraja khususnya, maupun rakyat Indonesia umumnya atas ketegasan yang ditunjukkan. 


\section{Kekayaan Budaya Indonesia}

Di dalam pentas dihadirkan berbagai macam tari-tarian yang merupakan kebudayaan berasal dari Sulawesi Selatan, maupun perpaduan dari kebudayaan lainnya di Indonesia. Berbagai macamnya kebudayaan tersebut menunjukkan kekayaan budaya Indonesia yang beraneka ragam. Adapun tarian tersebut sebagai berikut:

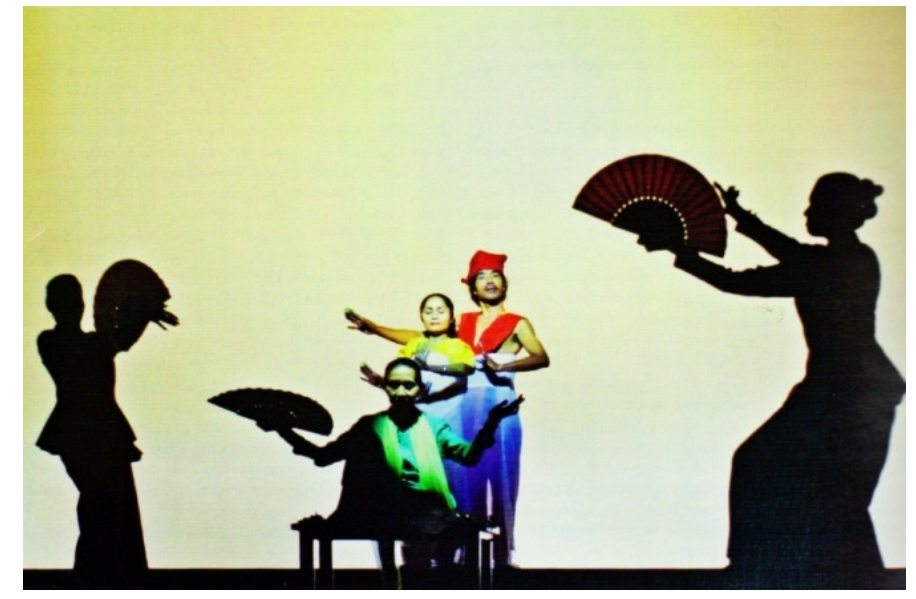

Tari Pakkarena: Pakkarena adalah tari tradisional yang berasal dari wilayah Bugis dan Makassar. Secara filosofis Tari Pakkarena bermakna perempuan yang bagaikan batu karang di tengah samudera.

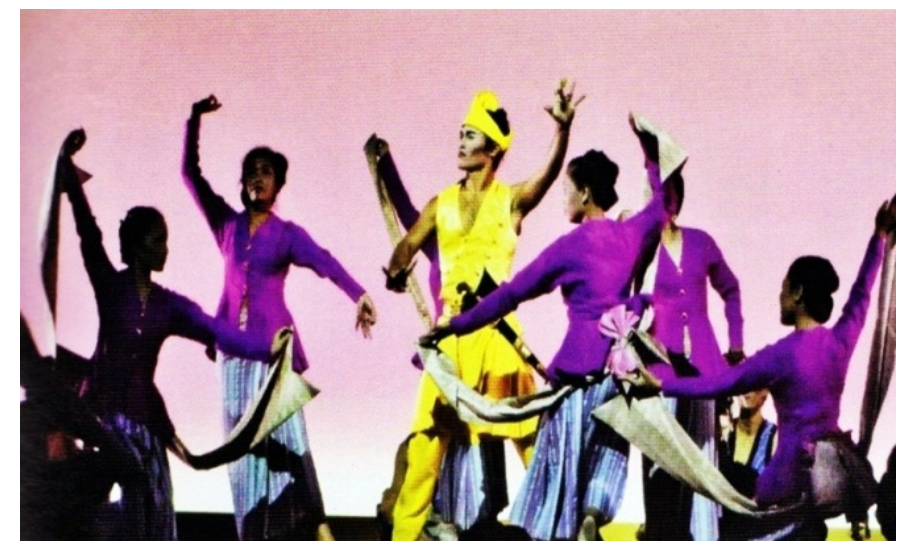

Tari Pajoge': Tari berpasangan terinspirasi yang berasal dari Kabupaten Bone. Tari pajoge' merupakan tarian yang dipertontonkan pada pesta raja dan umum. Sehingga tarian ini berfungsi sebagai tarian dan alat penghubung antara raja dengan rakyat, untuk mendekatkan hubungan supaya rakyat tetap cinta kepada rajanya dan sebaliknya.

Tari Padekko: Tari tradisional di wilayah Bugis dan Makassar yang dimainkan pada masa panen. Sementara orang mengalu beras, mereka menumbukkan alu dengan lampang, mengeluarkan suara indah sebagai tanda persahabatan. Tari ini dilakukan oleh sekelompok perempuan berpakaian baju bodo. Juga diringi oleh tabuhan gendang dan gong. Bunyi tumbukan lumbung padi seiring seirama dengan bunyi musik dari gendang dan gong.

Tari Galaganjur: Tarian ini berasal dari kepulauan Kodingareng. Tarian ini biasa dilakukan pada saat para nelayan merayakan pesta laut dan saat pesta bulan purnama. Tarian ini biasa dilakukan pada saat para nelayan merayakan pesta laut dan saat pesta bulan purnama. Selain 
itu para pelaut biasanya menarikan tari ini ketika mereka membuang sauh di pelabuhanpelabuhan jauh.

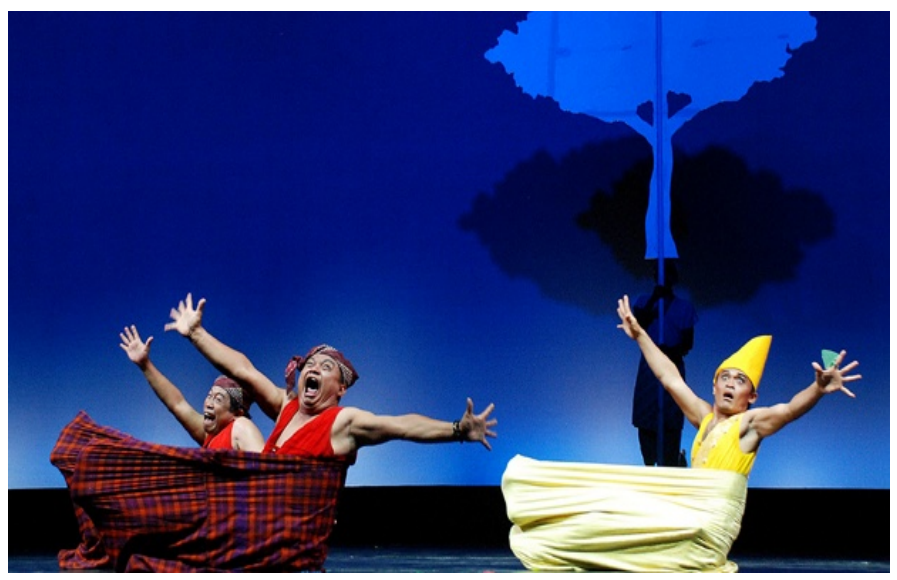

Tari Ma Lepa-Lepa: Permainan kapal sarung yang biasanya dimainkan oleh enam sampai delapan lelaki. Permainan ini mengajarkan persaudaraan, kerjasama, dan keberanian. Tari ini terinspirasi oleh permainan kapal sarung. Permainan ini sering dilakukan anak-anak selama musim hujan saat mereka tak diizinkan bermain di luar. Mereka lantas bermain di rumah panggung mereka, menggunakan sarung sebagai kapal. Dalam adegan ini terdapat nilai siri' (malu/harga diri) Sawerigading harus meninggalkan kampung halamannya dan kemudian berlayar menuju ke negeri Cina.

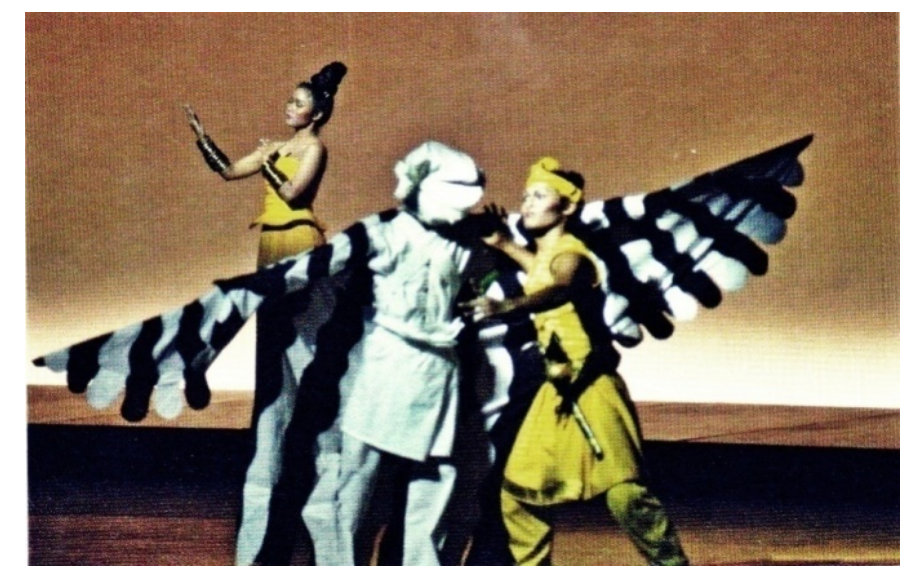

Tari Kondo Bulaeng: Tarian ini hidup dan berkembang di Desa Paropo, Makassar, dimana ia dipertunjukkan oleh sekelompok petani, nelayan, dan penjual sayur. Kondo (bangau putih) adalah tokoh khas dalam teater ini dan kadang dianggap sebagai tokoh kocak dan pada saat lain dipandang menyayat hati dan misterius. Dalam teater ini, kondo berperan sebagai mahkluk pembawa pesan bahwa hidup itu berharga. Pesan ini disampaikan dalam bentuk musik bercampur mantra. 


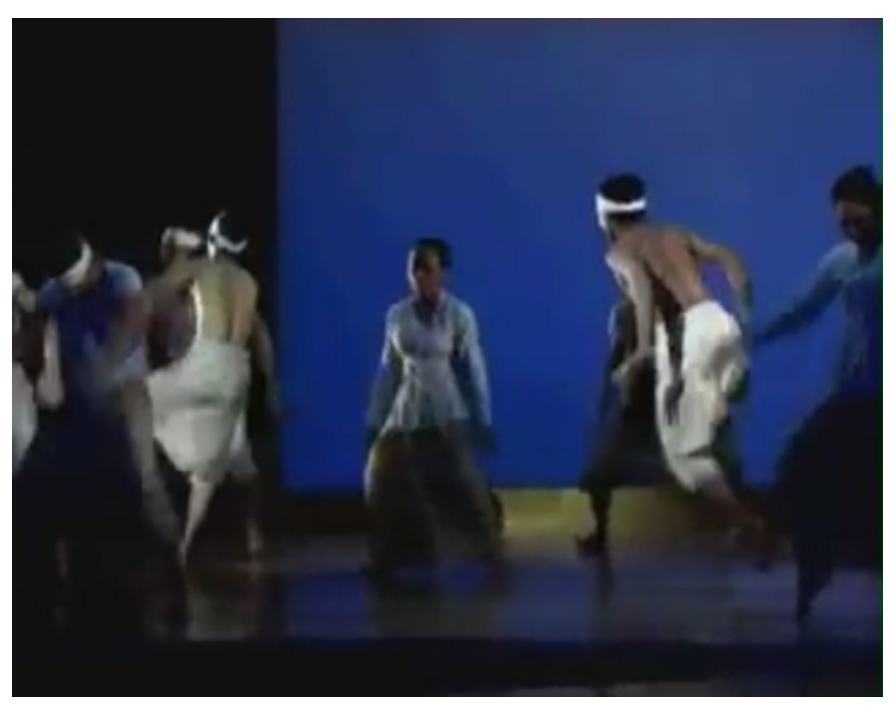

Tari Perang: Tarian ini terinspirasi oleh gerakan pencak silat, seni bela diri yang berasal dari Bugis, Makassar, Banten, dan Cina. Selain gerakan Pencak Silat, gerakan tari dan tari perburuan juga disertakan dalam pementasan.

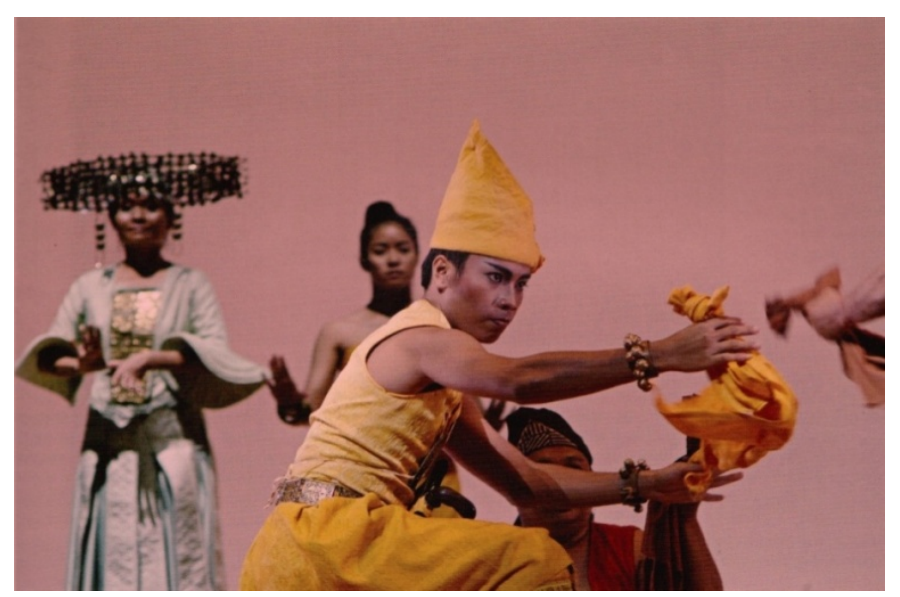

Tari Sabung Ayam (Pabitte Passapu): Gerakan-gerakan dalam adegan ini terinspirasi oleh gerakan permainan tradisional Bugiang disebut Pabitte Passapu. Tari ini berasal dari daerah Kajang di Bugis dan berkembang di kalangan-kalangan pemuda-pemudi Bugis Bulukumba.

\section{Sikap Malu dan Empati}

Siri na pessé (Bugis) / Siri’ na pacce (Makassar) / Malu dan Empati (Indonesia) adalah sebuah konsep yang sangat menentukan dalam identitas orang Bugis dan masyarakat Sulawesi Selatan pada umumnya. Konsep siri' mengacu pada perasaan malu dan harga diri sedangkan pessélpacce mengacu pada suatu kesadaran dan perasaan empati terhadap penderitaan yang dirasakan oleh setiap anggota masyarakat.

Di dalam pementasan teater I La Galigo nilai-nilai siri' di transformasikan pada beberapa adegan, diantaranya siri'Sawerigading sehingga ia berlayar ke negeri Cina, siri' Sawerigading pada saat lamarannya di tolak oleh We Cudaiq, siri' We Cudaiq pada saat mengetahui tentang keberadaan anaknya dan suaminya.

Walaupun melekat pada kebudayaan tradisional, namun kesan yang dibangun akan berdampak positif pada kebudayaan nasional. Dalam arti kata, pandangan yang terbangun dari pementasan tersebut yakni orang Indonesia memiliki karakter malu dan empati. 


\section{E. PENUTUP}

\section{Kesimpulan}

Dari pemaparan di atas, dapat disimpulkan bahwa upaya menjadikan pementasan teater I La Galigo sebagai sarana komunikasi nilai-nilai luhur budaya Indonesia di kancah internasional berjalan dengan sukses dan efektif. Hal ini tercermin dari kesuksesan pentas yang dilakukan di 12 tempat berbagai negara.

Walaupun secara umum tanggapan dari penonton tidak dapat diukur satu per satu, hal ini disebabkan komunikasi yang dilakukan secara massal, sehingga persepsi yang didapatkan bersifat absrak. Namun demikian melalui gerakan-gerakan komunikasi non-verbal yang disampaikan melalui pementasan serta mendapatkan sambutan yang selalu meriah dari pentas ke pentas merupakan representasi komunikasi satu arah yang dilakukan dengan baik serta tersampaikan kepada penonton.

Salah satu keuntungan menggunakan komunikasi non-verbal adalah penonton dapat mengerti jalannya sebuah cerita sekalipun tidak mengerti bahasa yang digunakan pada saat pementasan dilakukan. Sehingga kemungkinan terjadinya miskomunikasi antara penonton dengan pentas yang dipertontonkan semakin kecil. Maka dapat dikatakan bahwa pementasan teater I La Galigo menggunakan bahasa yang universal yakni gerakan/kinestetis.

Melalui pementasan teater ini juga tentunya berbagai pencitraan budaya Indonesia dapat mempengaruhi persepsi masyarakat internasional, sebagaimana tujuan dari diplomasi kebudayaan yakni memberikan dampak terhadap persepsi masyarakat negara lain (masyarakat yang menjadi penonton pentas tersebut).

Pada akhirnya nilai-nilai keberanian orang Indonesia, kekayaan budaya Indonesia, serta nilai karakter malu dan empati yang dimiliki oleh orang Indonesia dapat diantarkan dengan baik kepada para penonton melalui pementasan ini dan diharapkan dapat membangun persepsi positif tentang Indonesia.

\section{Rekomendasi}

Melalui makalah ini penulis mengajak seluruh pemerhati budaya daerah, serta instansi terkait seperti Kementerian Pariwisatan dan Ekonomi Kreatif, Kementerian Pendidikan dan Kebudayaan, serta Kementerian Luar Negeri untuk turut serta mempromosikan budaya daerah setempat ke kancah internasional. Upaya ini juga harus didukung kesediaan pekerja seni untuk meningkatkan kemampuannya dalam rangka menghadapi globalisasi yang menuntut kemampuan lebih yakni melakukan ekspor budaya ke negara lain.

Hal ini tentunya dapat meningkatkan daya tawar Indonesia di kancah internasional apabila dilakukan secara bersama-sama dalam rangka menunjukkan kekuatan diplomasi kebudayaan Indonesia dan keberagaman budaya Indonesia kepada dunia internasional. Semoga usaha ini menjadikan Indonesia menjadi negara terpandang karena budayanya diantara negara-negara lain. 


\section{BIBLIOGRAPHY}

CPAs. I La Galigo. (http://www.changeperformingarts.it/shows/galigo/ilg.html), diakses 10 November 2013.

Darwanto, Sasto. 2007. Televisi Sebagai Media Pendidikan. Pustaka Pelajar, Yogyakarta.

Dunia Sastra. Karya Sastra I La Galigo Yang Mendunia.

(http://duniasastra.com/index.php?option=com_content\&view=article\&id=182:karyasastra-i-la-galigo-yang-mendunia-\&catid=38:artikel-sastra\&Itemid=62), diakses 10 November 2013.

Effendi, Tonny Dian. 2011. Diplomasi Publik Jepang: Perkembangan dan Tantangan. Bogor: Ghalia Indonesia.

Effendy, Onong Uchjana. 1993. Ilmu, Teori, dan Filsafat Komunikasi. Bandung: PT Citra Aditya Bakti.

Muhtamar, Shaff. 2007. Masa Depan Warisan Luhur Kebudayaan Sulsel. Makassar: Pustaka Refleksi.

Prasad, Ugoran. I La Galigo and Beautiful Indonesia. (http://lebur.or.id/2010/09/16/robertwilson\%E2\%80\%99s-i-la-galigo-and-beautiful-indonesia/), diakses 10 November 2013.

Rakhmat, Jalaluddin. 1999. Metode Penelitian Komunikasi. Bandung: PT. Remaja Rosda Karya.

Santana, Edi. I La Galigo: Pujaan Dunia Yang Kembali.

(http://edisantana.blogspot.com/2011/06/i-la-galigo-pujaan-dunia-yang-

kembali.html), diakses 10 November 2013.

UNESCO. La Galigo. (http://www.unesco.org/new/en/communication-andinformation/flagship-project-activities/memory-of-the-world/register/full-list-ofregistered-heritage/registered-heritage-page-5/la-galigo), diakses 10 November 2013.

UNHAS. Pemikiran La Galigo Universal. (http://www.unhas.ac.id/content/pemikiran-lagaligo-universal), diakses 10 November 2013.

Warsito, Tulus, dan Wahyuni Kartikasari. 2007. Diplomasi Kebudayaan: Konsep dan Relevansi bagi Negara Berkembang: Studi Kasus Indonesia. Yogyakarta: Penerbit Ombak. 